\title{
Results of Open Lateral Internal Sphincterotomy for Chronic Anal Fissure: A Case Series
}

\author{
Authors \\ Anand Deoraj ${ }^{1}$, Kanchan Sonelal Baitha ${ }^{2 *}$, Prem Prakash ${ }^{3}$ \\ ${ }^{1,2,3}$ Department of General Surgery, Indira Gandhi Institute of Medical Sciences, Patna, Bihar \\ *Corresponding Author \\ Kanchan Sonelal Baitha \\ Department of General Surgery, Indira Gandhi Institute of Medical Sciences, Patna, Bihar, India
}

\begin{abstract}
Now a days, eating habits of general public is switching on to low fiber diet leading to constipation and subsequently to anal fissure. It causes ischemia in the anal lining. Constipation, elevated anal pressure and ischemia produces a vicious cycle leading to chronic anal fissure which just refuses to heal causing significant morbidity. The present study aims to evaluate safe and effective surgical method for the treatment of chronic anal fissure in the form of subcutaneous lateral internal sphincterotomy. We conducted a prospective study comprising of 58 patients suffering from chronic anal fissure from June 2017 to June 2019. Subcutaneous lateral internal sphincterotomy was done and patients were evaluated for pain relief, complications and recurrence rates. Almost all patients (94.82\%) had complete pain relief after 8 weeks. Per rectal minimal bleeding for 2-3 days post operatively was the most common complication (25-86\%) while a temporary incontinence to flatus was seen in $5.1 \%$ of the patient. No incontinence to stool was seen. No recurrence was seen in the follow-up period of 8 months. We found subcutaneous lateral sphincterotomy safe and effective treatment method for chronic anal fissure.
\end{abstract}

\section{Introduction}

Anal fissure is a very common anorectal disease. Its defined as a breach in the anoderm below the dentate line ${ }^{[1]}$. It can be acute or chronic. Most of the patients have a history of chronic constipation while others have a prior episode of diarrhea. Pain during the defecation is the main presenting feature. This pain may last for minutes to hours after defecation and can be so severe that patients try to avoid defecation so as to avoid pain. This leads to further constipation. Per rectal fresh blood in the pan is the second most common complain. Raised internal anal sphincter spasm in chronic cases leads to ischemia of the affected area and subsequent poor wound healing and recurrence ${ }^{[2]}$. Chronic anal fissure is a fissure that lasts more than 8 weeks ${ }^{[3]}$. Chronic fissures are identified by a hypertrophied anal papilla and a skin tag. Initial treatment of anal fissure is conservative. Stool softeners, high fiber diet and warm sitz bath is all that is required ${ }^{[4]}$. Those who fail this treatment are subjected to lateral internal sphincterotomy which has now become the gold standard surgical treatment for chronic anal fissure ${ }^{[5][6]}$. In this study our aim is to present the outcome of subcutaneous lateral partial internal sphicterotomy for chronic anal fissure in terms of complications, recurrance rate and patient satisfaction. 


\section{Materials and Methods}

A total of 58 lateral internal partial sphincterotomy was performed on the outpatient basis between June 2017 - June 2019. Ours was a prospective study. All the patients included in the study had a history of failed conservative management.

Inclusion Criteria- patients suffering from anal fissure for more than 8 weeks.

Exclusion Criteria- patients with coexisting anal abscess, anal fistul, hemorrhoid, inflammatory bowel disease and patients with previous history of any anorectal surgery.

Preoperatively, anal tone was assessed clinically. Patients with reduced anal tone were also not included in the study.

The procedure was performed in lithotomy position. Preoperative prophylactic enema and antibiotics were not used. Local anesthesia with lidocaine was given. Intersphincteric groove was recognized by gently sliding the palpating finger out of the anal canal. A number 11 surgical blade was inserted through this groove at 3 or 9 o'clock and advanced cranially to the level of the dentate line. The blade was then turned medially towards the anal canal and fibers of the internal sphincters were cut. Care was taken to only divide up to half of the internal sphincters width below the dentate line. The blade was withdrawn and finger pressure was applied to achieve homeostasis. The defect was not stitched. As it was a day care procedure all the patients were allowed to go back home the same day and resume their normal diet and defecation. Post operatively patients were advised sitz bath, stool softeners and a single dose of intravenous antibiotics and pain killers in the hospital and oral pain killers for use at home on as and when basis.

\section{Result}

Out of the 58 patients who were included in the study the most common age group was 21-30 years $(34.4 \%)$ [Table 1]. Overall 25 patients were male and 33 female. The main complain in the majority of the patient was pain during defecation
$(86.2 \%)$ and per rectal bleeding either during and/or after defecation (75.86 \%). Chronic constipation was a close third $(68.9 \%)$ Table 2.

The median duration of the disease was 22 months ranging from 2 months to 34 months. Relief of pain in terms of patient satisfaction was evaluated after $1^{\text {st }}$ week, $3^{\text {rd }}$ week, $5^{\text {th }}$ week and $8^{\text {th }}$ week from the day of operation Table 3 .

In terms of complications in the post operative period minimal amount of bleeding was encountered in 15 patients up to 2-3 days postoperatively which did not required any surgical intervention. 5 patients had wound infection which was treated by oral/injectable antibiotics. Out of these five patients, two had diabetes.

3 patients developed temporary incontinence to flatus which was controlled over a week or two. None of the patients developed incontinence to stool Table 4.

Patients were followed up to 6 months post-op.

Table 1. Showing age distribution.

\begin{tabular}{|l|c|c|}
\hline Age group (years) & No. of operated patients & Percentage \\
\hline$<20$ & 2 & 3.4 \\
\hline $21-30$ & 20 & 34.4 \\
\hline $31-40$ & 15 & 25.8 \\
\hline $41-50$ & 10 & 17.2 \\
\hline $51-60$ & 6 & 10.3 \\
\hline$>60$ & 5 & 8.6 \\
\hline
\end{tabular}

Table 2. Signs/Symptoms of patients

\begin{tabular}{|l|c|c|}
\hline \multicolumn{1}{|c|}{ Signs/Symptoms } & No. of patients & Percentage \\
\hline Pain during defaecation & 50 & 86.2 \\
\hline Per rectal bleeding & 44 & 75.86 \\
\hline Chronic constipation & 40 & 68.9 \\
\hline
\end{tabular}

Table 3. Results of pain relief

\begin{tabular}{|l|c|c|}
\hline Weeks & No. of patients & Percentage \\
\hline $1^{\text {st }}$ week & 30 & 51.7 \\
\hline $3^{\text {rd }}$ week & 42 & 72.41 \\
\hline $5^{\text {th }}$ week & 51 & 87.93 \\
\hline $8^{\text {th }}$ week & 55 & 94.82 \\
\hline
\end{tabular}

Table 4. Post-op complications

\begin{tabular}{|l|c|c|}
\hline Complications & $\begin{array}{c}\text { No. of } \\
\text { patients }\end{array}$ & Percentage \\
\hline Per rectal bleeding & 15 & 25.86 \\
\hline Wound infection & 5 & 8.6 \\
\hline Temporary incontinence to flatus & 3 & 5.1 \\
\hline Temporary incontinence to stool & 0 & 0 \\
\hline $\begin{array}{l}\text { Permanent incontinence to } \\
\text { stool/flatus }\end{array}$ & 0 & 0 \\
\hline
\end{tabular}




\section{Discussion}

The main aim of lateral internal sphincterotomy is to reduce the spasm of internal sphincter by $18 \%$ $50 \%$ thereby increasing the blood flow to the anoderm leading to improvement between $82 \%$ to $100 \%{ }^{[7]}$. In our study the most common age group affected was 21 to 330 years $(34.4 \%)$ i,e younger while in most of the studies done on foreign soil age group 31 to 40 years were common victims ${ }^{[8][9]}$. It may be due to changing diet habit to low fiber diet causing constipation and subsequent chronic anal fissure.

Out of 58 patients (\%) were female. It is usually seen that male and females are equally affected ${ }^{[10]}$. In our part of the world female general surgeons are less in number than their male counterparts. Due to social and cultural factors female population is shy to get examined by male surgeons until their disease progress to chronic stage recommending surgical intervention.

Araujo et al, in his prospective clinical trial reported pain relief rate of $93 \%$ after two weeks and $100 \%$ after $8^{\text {th }}$ week $^{[11]}$. Similarly in our study most of the patients $(94.82 \%)$ reported complete pain relief after $8^{\text {th }}$ week.

In our study temporary per rectal bleeding lasting for 2-3 days and occurring only during defecation was seen as the most frequent complication. Wound infection rate was $8.6 \%$ which responded with oral/iv antibiotics. No case progressed to anal fissure. In a study by Shafiq ullah et al, wound infection rate was $4 \%$ in both open and closed methods of lateral internal sphincterotomy ${ }^{[12]}$.

Fecal incontinence is the most dreaded complication. It depends on many factors like age, anatomic differences between male and females, previous pelvic surgery and on surgeon's skill. Generally, it last up to few weeks but may even last up to a year. In our study temporary incontinence to flatus was seen in $5.1 \%$ of patients while no patients reported incontinence to stool.

In the follow- up period of 6 months no cases reported recurrence. Study done by E-Ram et al had shown a recurrence rate of $2 \%$ with average follow-up of 11.2 months $^{[13]}$.

\section{Limitations}

Ours was a single centre study with a small sample size. Randomized clinical controll trials with a large sample size are recommended. We didn't check anal pressure by anal manometer because of limited facilities available at our centre. Comparison with other treatment methods was not done. Follow-up period was short (8 months).

\section{Conclusion}

Subcutaneous lateral internal partial sphincterotomy is safe and a very effective technique in the management of chronic anal fissure.

\section{References}

1. Brady JT, Althans AR, Neupane R, et al. Treatment for anal fissure: is there a safe option? Am J Surg. 2017;214:623e628.

2. Glover, et al., High-dose circumferential chemodenervation of the internal anal sphincter: a new treatment modality for uncomplicated chronic anal fissure: a retrospective cohort study (with video), Int. J. Surg. 23 (2015) 1e4.

3. Wald, et al., ACG clinical guideline: management of benign anorectal disorders, Am. J. Gastroenterol. 109 (8) (2014) 1141e1157

4. Perry WB, Dykes SL, Buie WD, Rafferty JF. Standards practice task force of the American Society of Colon and Rectal Surgeons Practice parameters for the management of anal fissures (3rd. revision). Dis Colon Rectum. 2010;53: $1110 \mathrm{e} 1115$.

5. Nelson RL, Chattopadhyay A, Brooks W, Platt I, Paavana T, Earl S. Operative procedures for fissure in ano. Cochrane Database Syst Rev. 2011;9:CD002199.

6. Hsu TC, MacKeigan JM. Surgical treatment of chronic anal fissure. A retrospective study of 1753 cases. Dis Colon Rectum. 1984;27:475e478. 
7. Poh A, Tan KY, Seow-Choen F. Innovations in chronic anal fissure treatment: a systematic review. World J Gastrointest Surg. 2010;2:231e241.

8. Tauro LF, Shindhe VV, Aithala PS, Martis JJ, Shenoy HD. Comparative study of glyceryl trinitrate ointment versus surgical management of chronic anal fissure. Indian Journal of Surgery. 2011 Aug;73(4):268-77.

9. Oh C, Divino CM, Steinhagen RM. Anal fissure, 20 year experience. Diseases of the colon and rectum. 1995;38(4):378-82.

10. Jonas, et al., Surgical Treatment: Evidence-based and Problem-oriented. Munich: Zuckschwerdt, 2001. Available from: http://www.ncbi.nlm.nih.gov/ books/NBK6878/.

11. Araujo SE, Sousa MM, Caravatto PP, Habr-Gamai A, Cecconello I. Early and late results of topical diltiazem and bethanechol for chronic anal fissure: a comparative study. HepatoGastroenterology. 2010;57:81e85.

12. Shafiq ullah, Muhammad Nadeem, Nishtar Closed versus open lateral internal sphincterotomy in chronic anal fissure: a comparative study of postoperative complications \& results. The Pakistan Journal of Medical Research. 2004;43:1.

13. Ram E, Vishne T, Lerner I, Dreznik Z. Anal dilatation versus left lateral sphincterotomy for chronic anal fissure: a prospective randomized study. Techniques in Coloproctology. December 2007. 